\section{PRTCM: A FORTRAN subroutine for rapid observation of correlations within a large correlation matrix}

\author{
JAMES H. STRAMLER \\ Biology Department, Texas A\&M University, \\ College Station, Texas 77843
}

and

\section{JAMES L. LEWIS \\ Spacecraft Design Division, NASA Johnson Space Center, Houston, Texas 77058}

As multivariate designs become more frequently used and more variables are employed, any computed correlation matrices become unwieldy in terms of one's ability to recognize patterns among the coefficients. This is particularly true when using statistical packages such as SPSS (Nie, Hull, Jenkins, Steinbrenner, \& Bent, 1975) and SAS (Helwig \& Council, 1979), which partition correlation matrices into several segments if more than five or six variables are involved.

While correlation matrices are often submitted to further processing, such as factor analysis, the matrices themselves are often of interest. PRTCM was developed to present the basic information contained in large correlation matrices as a single entity. In doing so, it permits possible visualization of patterns within the matrix and may serve a primitive cluster-analysis function.

The subroutine was written to meet a need for examining correlations between bands of power across several channels of EEG and EMG data. As such, it provides breaks in the matrix after a specified number of rows/columns to indicate different channels. This feature may be removed by deletion of some DO loops, if desired.

PRTCM produces its output by taking the absolute value of each correlation coefficient and multiplying it by 10 . After removal of the decimal portion, the singledigit positive integer remaining is converted to its corresponding ASCII representation, stored in a vector, and printed. For example, a correlation coefficient of -.53 would be represented by an ASCII 5 in its appropriate element in the output matrix.

The conversion to ASCII permits a quite general routine that can accept any size matrix without the necessity of changing FORMAT statements.

An input parameter (FACTOR) permits user selection of rounding in presenting the coded matrix. To be conservative, we have used a value of .00001 to prevent machine storage from causing unintended decreases in cases in which a .6 correlation might be stored as .59999 . . . . Any desired value can be used here, however, to determine rounding characteristics.
Either single- or double-precision matrices may be used. Conversion between the two is accomplished by exchanging two comment cards for two program cards in the subroutine.

Input. PRTCM has five input parameters. Two of these are the matrix and its order. Two others are parameters that indicate how many breaks (blank columns and rows) are to be placed in the printed matrix (NBRKS) and how many columns (rows) are to be printed between each break (NUMBR). The fifth parameter (FACTOR) determines whether rounding is made to the next higher 10 th when coding the matrix.

The routine accepts any appropriately dimensioned full storage mode matrix, subject to limitation only by the number of printer columns available. The maximum order may be determined from: number of printer columns - $(10+$ NBRK $)$.

Output. A sample output from PRTCM using artificial data is provided in Figure 1. All characters are printed as ASCII.

All four sides of the matrix are bordered with row or column numbers for ease in locating any particular element. The row numbers contain three digits if the matrix is larger than order 100 , but column numbers do not register the third digit.

\section{COOED CORFELATION MATRIX}

\begin{tabular}{|c|c|c|c|c|c|}
\hline $\begin{array}{l}03- \\
03- \\
05- \\
05- \\
06-\end{array}$ & $\begin{array}{l}-23456 \\
5-7890 \\
90-234 \\
345-78 \\
7890-2 \\
12345-\end{array}$ & $\begin{array}{l}789012 \\
123456 \\
567890 \\
901234 \\
345678 \\
799012\end{array}$ & $\begin{array}{l}345678 \\
789012 \\
123456 \\
567890 \\
901234 \\
345678\end{array}$ & $\begin{array}{l}901234 \\
345678 \\
799012 \\
123496 \\
567090 \\
901234\end{array}$ & $\begin{array}{l}=01 \\
=02 \\
=03 \\
=04 \\
=05 \\
=06\end{array}$ \\
\hline 11 & $\begin{array}{l}567890 \\
901234 \\
345678 \\
789012 \\
123456 \\
967890\end{array}$ & $\begin{array}{l}-23456 \\
5-7890 \\
90-234 \\
345-78 \\
7890-2 \\
12345-\end{array}$ & $\begin{array}{l}789012 \\
123456 \\
567890 \\
901234 \\
345678 \\
789012\end{array}$ & $\begin{array}{l}345678 \\
709012 \\
123456 \\
567890 \\
901234 \\
345678\end{array}$ & $\begin{array}{l}=07 \\
=08 \\
=09 \\
=10 \\
=11 \\
=12\end{array}$ \\
\hline $\begin{array}{l}13- \\
10- \\
150 \\
10- \\
18-\end{array}$ & $\begin{array}{l}901234 \\
345678 \\
789012 \\
123456 \\
567890 \\
901234\end{array}$ & $\begin{array}{l}567890 \\
901234 \\
345678 \\
789012 \\
123456 \\
567890\end{array}$ & $\begin{array}{l}-23456 \\
5-7090 \\
90-234 \\
345-78 \\
7890-2 \\
12345-\end{array}$ & $\begin{array}{l}789012 \\
123456 \\
567890 \\
901234 \\
345678 \\
789012\end{array}$ & $\begin{array}{l}=13 \\
=14 \\
=15 \\
=16 \\
=18\end{array}$ \\
\hline $\begin{array}{l}20 \\
21 \\
22 \\
23\end{array}$ & $\begin{array}{l}345678 \\
789012 \\
123456 \\
567890 \\
901234 \\
345678\end{array}$ & $\begin{array}{l}901234 \\
345678 \\
789012 \\
123456 \\
567890 \\
901234\end{array}$ & $\begin{array}{l}567090 \\
901234 \\
345678 \\
709012 \\
123456 \\
567890\end{array}$ & $\begin{array}{l}-23456 \\
5-7090 \\
90-234 \\
345-78 \\
7890-2 \\
12345-\end{array}$ & $\begin{array}{l}=19 \\
=20 \\
=21 \\
=22 \\
=23 \\
=24\end{array}$ \\
\hline & 12345 & $\begin{array}{l}1111 \\
7890\end{array}$ & $\begin{array}{l}111 \\
345\end{array}$ & 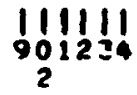 & \\
\hline
\end{tabular}

Figure 1. Sample printout of a correlation matrix of order 24 using PRTCM. 


\section{STRAMLER AND LEWIS}

The matrix output itself consists of positive singledigit integers representing the absolute value of the correlation coefficient multiplied by 10 . The main diagonal is represented by dashes.

Computer and Language. The routine is written in FORTRAN and was developed in its current form on an Amdahl $470 \mathrm{~V} / 6$ computer, an IBM-compatible machine. An earlier version, also written in FORTRAN, was developed using a Hewlett-Packard $21 \mathrm{MX}$ minicomputer and will only handle matrices of less than order 100 .

The core requirement is minimal. The subroutine contains 129 statements, including some comment cards. The largest internally dimensioned structure is a vector that should be set for the number of printer columns available.

Availability. Listings of PRTCM are available from the senior author free of charge.

\section{REFERENCES}

Helwig, J. T., \& Council, K. A. (Eds.). SAS users guide. Raleigh, N.C: SAS Institute, 1979.

Nie, N. H., Hull, C. H., Jenkins, J. G., Steinbrenner, K., \& Bent, D. H. Statistical package for the social sciences (2nd ed.). New York: McGraw-Hill, 1975.

(Accepted for publication July 1, 1980.) 